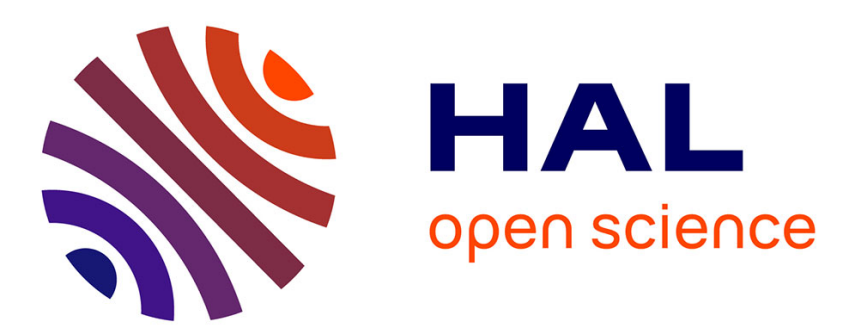

\title{
The meaning of French "implication" contour in conversation
}

Cristel Portes, Uwe Reyle

\section{To cite this version:}

Cristel Portes, Uwe Reyle. The meaning of French "implication" contour in conversation. Speech Prosody 2014, May 2014, Dublin, Ireland. pp.413-417. hal-01507721

\section{HAL Id: hal-01507721 \\ https://hal.science/hal-01507721}

Submitted on 9 Feb 2022

HAL is a multi-disciplinary open access archive for the deposit and dissemination of scientific research documents, whether they are published or not. The documents may come from teaching and research institutions in France or abroad, or from public or private research centers.
L'archive ouverte pluridisciplinaire HAL, est destinée au dépôt et à la diffusion de documents scientifiques de niveau recherche, publiés ou non, émanant des établissements d'enseignement et de recherche français ou étrangers, des laboratoires publics ou privés. 


\title{
The meaning of French "implication" contour in conversation
}

\author{
Cristel Portes $^{1}$, Uwe Reyle ${ }^{1,2}$ \\ ${ }^{1}$ Aix-Marseille Université, CNRS, LPL, UMR 7309, Aix-en-Provence, France \\ ${ }^{2}$ IMS, University of Stuttgart \\ cristel.portes@lpl-aix.fr, uwe.reyle@ims.uni-stuttgart.de
}

\begin{abstract}
French intonational contours inventory has a rising-falling tune which presents very interesting semantic properties. It has been called "intonation d'implication" by Delattre [1] suggesting that the contour triggers an implicit meaning, i.e. an implicature in Gricean terms. Besides, the "implication" contour has been claimed to convey various attitudinal meanings from obviousness to exasperation, and also to mark contrastive focus. The aim of the present paper is to give a unified account of these seemingly differing semantic descriptions of the "implication" contour in French, using a dynamic semantic framework, namely Discourse Representation Theory (DRT). We claim that the main semantic component of the "implication" contour is to convey a contradiction (or a contrast). We first sketch our DRTtheoretical approach, and then apply it to occurrences of the "implication" contour in a corpus of conversational dialogue.
\end{abstract}

Index Terms: intonation, intonational meaning, "implication" contour, semantics, Discourse Representation Theory, dialogue, conversation, French

\section{Introduction}

The rising-falling contour called "intonation d'implication" (implication contour) by Delattre [1] is one of the tunes of French that has been attributed a whole range of different kinds of meaning. Delattre himself proposed that the meaning of the contour is to link the meaning of the actual utterance to an implicit content which must be recovered from the context: it may convey various meanings such as obviousness, exasperation or, on the contrary, politeness. Another role attributed to French "implication" is related to a high degree of expressivity or emphasis. For instance Rossi called it "expressème" ([2], [3]) and Di Cristo \& Hirst [4] spoke about "emphase contrastive" (contrastive emphasis). This latter proposal refers to another meaning that has been attributed to the contour, i.e. contrast. A related idea expressed in more semantic terms is found in Mertens' and in Ladd's more recent proposals ([5], [6]) where the contour is said to convey speaker commitment. These approaches give very detailed and rich accounts of the phonetic and phonological aspects of the "implication contour" in French. However, its semantic aspects are mostly presented in broad attitudinal terms, which do not account for the dialogical dimension of its meaning.

On the other hand, the semantic literature gives more and more attention to both dialogue and intonation. For instance, working in a semantic framework developed by Ginzburg [7], Beyssade \& Marandin [8] proposed that intonational meaning relies crucially on the attribution of attitudes to the addressee. For Gunlogson [9], rising intonation in declarative questions expresses the speaker commitment to a proposition but, at the same time, marks it as contingent on ratification by the addressee. Very recently, Groenendijk \& Roelofsen [10] have proposed an "inquisitive" semantic framework where assertions bear inquisitive contents that are inviting responses from other participants. Using this framework, Westera [11] claimed that final rises in English signal that a conversational maxim is violated. And Portes \& Reyle [12] followed Krifka's proposal [13] to interpret speech acts by development of spaces of commitments assigned to the discourse participants, in order to explain the meaning of four contours of French inventory.

Convoking both phonological and semantic literature, the present paper aims at showing that French "implication" contour conveys a complex meaning whose different dimensions can be accounted for in a dynamic semantic approach modeling dialogue. After a brief exposal on the phonology of the contour in section 2, section 3 develops a semantic account of its meaning using Discourse Representation Theory (DRT). Then, section 4 verifies the reliability of the proposed unified meaning in a corpus of conversational data, before section 5 concludes.

\section{The phonology and phonetics of French "implication" contour}

The "implication" contour is not the only rising-falling movement of French intonational inventory. It is sometimes (but must not be) mixed up with a rise-fall, the high f0 target of which is localized on the penultimate syllable of the accentual phrase (AP: the basic constituent of French phrasing), while it occurs on the final (full) syllable for the "implication" contour. The present section gives a brief account of what must be known about the phonology and phonetics of the contour under investigation here.

The clearest account of the phonological contrast and the phonetic implementation of the "implication" rise-fall has been given by Post ([14], [15]). Phonologically, she distinguished this contour from the fall from penultimate contour by attributing two different pitch accents to them. Hence, the former is coded $\mathrm{LH}^{*} \mathrm{~L} \%$ with a monotonal $\mathrm{H}^{*}$ pitch accent while the latter is coded $\mathrm{LH}+\mathrm{H} * \mathrm{~L} \%$ with a bitonal $\mathrm{H}+\mathrm{H}^{*}$ pitch accent.

Phonetically, the "implication" contour $\mathrm{LH}^{*} \mathrm{~L} \%$ is said to be implemented with a global difference in temporal alignment compared to the rise $\mathrm{LH}^{*} \mathrm{H} \%$, the $\mathrm{H}$ target of which also occurs on the last syllable of the AP. The alignment of $\mathrm{LH}^{*} \mathrm{~L} \%$ is earlier both for its initial L target and for its $\mathrm{H}^{*}$ target as shown in Figure 1 and 2 below. This regular phonetic difference has been confirmed by quantitative measures in a large corpus study on naturally occurring data carried out by Portes [16]. 


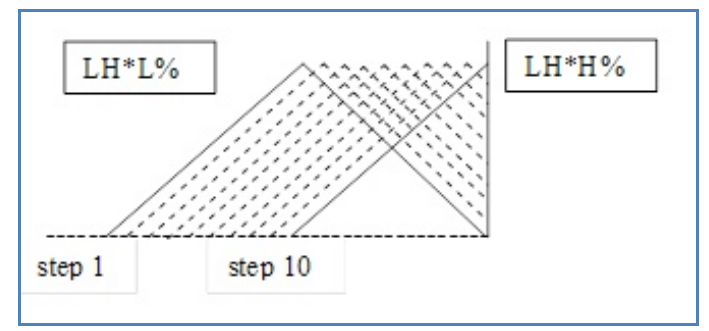

Figure 1: Design of the ten step alignment continuum between the "implication" contour $L H^{*} L \%$ and the rising contour $\mathrm{LH}^{*} \mathrm{H}_{\mathrm{O}} \mathrm{u}$ used by Post in a categorical perception experiment. The temporal alignment of both the first $L$ and the $H^{*}$ targets are delayed from step 1 to 10.

Another important aspect of the "implication" contour is that it can occur at the end of an intonational phrase (IP) but also at the end of an intermediate phrase (ip). In this case the final low boundary tone $\mathrm{L} \%$ may be preceded by a low phrasal tone L- triggered by a narrow focus occurring on a non final constituent, as proposed by Jun \& Fougeron [17]. This Lphrasal tone spreads until the end of the IP up to the L\%, triggering deaccentuation on the material following the narrow focus constituent, at least when it is marked as background information by the speaker. Figure 2 depicts a corpus example of such a use of the "implication" contour borrowed from Bigi and colleagues [18].

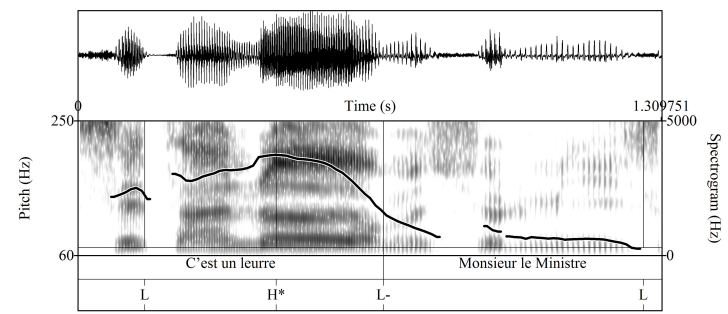

Figure 2: A corpus example of an ip-final "implication" contour resulting in a $L H^{*} L-L \%$. The background part of the utterance, which is also syntactically right detached, is deaccented through the spreading of the phrasal tone $L$-. The text is "C'est un leurre, Monsieur le Ministre" (This is an illusion, Minister).

\section{A DRT account of the meaning of the French "implication" contour}

We now come back to the meaning of the "implication" contour. In the semantics of French intonation proposed by Beyssade and Marandin [8], this tune belongs to a group of "non falling contours" which are appropriate in what they call a "defective" context (following Stalnaker [19]), namely a context where the assumed beliefs of speaker and addressee are not compatible. More recently, Portes and Beyssade [20] proposed a compositional account of the meaning of French intonation where the "implication" contour is said to convey disagreement. The data in (1) confirm this claim. The contours are depicted with the following codes: $\mathrm{F}$ for the simple fall and IRF for the "implication" rise-fall.
(1) a. L1: Dans cette ville, il n'y a de restaurants que pour les carnivores. $\mathrm{F}$

In this town, there are restaurants only for carnivores.

b. L2: Non, il y a un restaurant végétarien $\mathrm{F}$

No, there is a vegetarian restaurant.

\section{c. L2: Il y a un restaurant végétarien IRF}

There is a vegetarian restaurant.

Consider the declarative in (1b). Its content $\mathrm{q}$ contradicts the assertion p made by L1 in (1a) (with a falling contour). It has been stressed by several authors (cf. Lascarides and Asher [21]) that disagreement should be made explicit, whereas undenied commitments persist in dialogue. For that reason, L2 explicitly rejects $p$ by the preceding "no" in case she wants to use the simple fall $\mathrm{F}$, as in (1b). But (1c) shows that L2 has other means to mark the rejection, and hence to react negatively on the expectation to add $\mathrm{p}$ to the common ground (CG), namely by her use of the "implication" contour IRF. This shows that the use of the "implication" contour in (1c) conveys the rejection of p just as the explicit "no" does in (1b).

Conversely, the "implication" contour IRF is not appropriate in $(2 \mathrm{~b})$ below contrary to the simple fall $\mathrm{F}$. This is because, in this case, there is no contradiction between $\mathrm{p}$ (the content of (2a) which is equivalent to that of (1a)) and r, the content of $(2 b)$.

(2) a. L1: Dans cette ville, il n'y a de restaurants que pour les carnivores. $\mathrm{F}$

In this town, there are restaurants only for carnivores.

\section{b. L2: Il n'y a pas de restaurant végétarien $\mathrm{F}$ but \#IRF}

There is no vegetarian restaurant.

Examples (1) and (2) suggest that the "implication" contour expresses a contradiction, or more generally a contrast. We claim that the implication contour presupposes ${ }^{I}$ such a contrast and that the different meanings of the contour can be explained on the basis of how this presupposition is resolved in the context of the dialogue. The main ingredients of the explanation are:

(i) Following [22] we assume that the defining criterion for "contrast" is the awareness of a manageable set of alternatives; the set of alternatives is given by the context.

(ii) Implicit Questions under Discussion (QUDs) are present at any stage of the discourse ([22], [23], [7]).

(iii) The interpretation of the implication contour presupposes a contrast, i.e. a set of alternatives to be identified with a contextually given QUD. The particular meaning of the contour then follows from the information that has brought about this QUD at the first place.

To make this more precise, consider (1). L1's statement involves the focus-sensitive operator "il n'y a que" (only). In the framework of an alternative semantics for focus ([24]) such an operator requires a set of alternatives, e.g. "What kinds of restaurants are there in Aix?", which can be considered as the QUD to which L1 tries to give an answer by his asserting (1a). The meaning of "il n'y a que" implies that the QUD is fully answered, i.e. all alternatives except $p$ are

\footnotetext{
1 A presupposition is a condition associated with a sentence or utterance which must be fulfilled in the context in which the utterance occurs (or the sentence is used) so that this sentence or utterance succeeds in determining a well-defined proposition.
} 
excluded. If we assume that there are three types of restaurants, non-vegetarians (p), vegetarians (q) and vegans $(\mathrm{r})$, that are relevant in the discussion of $\mathrm{L} 1$ and L2, we have before L1's uttering (1a) the QUD $=\{\mathrm{p}, \mathrm{q}, \mathrm{r}\}$. With his utterance (1a), L1 proposes a complete answer to L2, i.e. a fully resolved QUD $=\{p\}$, as shown in the final line of the following diagram.

\begin{tabular}{|l|l|l|}
\hline utterance & presupposition & QUD \\
\hline & & $\{p, q, r\}$ \\
\hline$p \quad(=(1 a))$ & & \\
\hline & & $\{p\}$ \\
\hline
\end{tabular}

According to our assumption the implication contour on (1c) triggers the presupposition that there must be a contrast, given by a contextually relevant set of alternatives to q. In the context of (1) we may assume that the alternatives are $\{\mathrm{p}, \mathrm{q}, \mathrm{r}\}$ again. But if we look at the utterance (1c) in isolation, this contrast is underspecified. The only thing we know is that there must be alternatives to q, i.e. the contrast has the form $\{q\} \cup C$, where $C$ is a non-empty, contextually determined set of alternatives to q. In our example (1), C should be identified with $\{\mathrm{p}, \mathrm{r}\}$. But this is not possible as long as QUD consists of the singleton set $\{\mathrm{p}\}$ - as it does right after the assertion of (1a). Note that (1c) uttered with a falling contour would contradict (1a) without explicit marking. This is not acceptable, because non-acceptance must be made explicit as it is done, e.g., by asserting $\neg$ p (by means of the $\mathrm{No}$ ) in (1b) or, by uttering (1c) with the implication contour. And, once (1a) is rejected by the implication contour, the original QUD is accessible and the presupposition triggered by the contour can be resolved to $\{\mathrm{p}, \mathrm{q}, \mathrm{r}\}$. At the same time, $\mathrm{L} 2$ claims to resolve the QUD by his assertion of $\neg p^{1}$.

\begin{tabular}{|c|c|c|}
\hline$\ldots$ & $\ldots$ & $\ldots$ \\
\hline$q \quad(=(1 . c))$ & $\{q\} \cup C$ & $\{p, q, r\}$ \\
\hline & $C=\{p, r\}$ & $\{q\}$ \\
\hline
\end{tabular}

The dialogue (3), taken from the CID-corpus, has the same structure as (1). The situation and the interpretation of the implication contour is, however, different, because YM's assertion only partially settles the original QUD, i.e. the implicit question of "what there is, that they have at their windows".

(3) YM : il y a il y a pas de volets quoi

There are there are no shutters

\footnotetext{
${ }^{1}$ In [25], we gave a formal analysis of the meaning of the implication contour that corresponds to the rejection and contradiction case of (1). We assumed that the use of the contour in an utterance of $p$ triggers a presupposition that is more specified than the one we assume in this paper, because the contradiction that explains this particular meaning of the contour is already built in the presupposition itself. This implies that the contour is considered ambiguous between the particular meaning we investigated and the other meanings described in the literature. This paper starts from the assumption that the implication contour is not ambiguous, but underspecified and receives its final meaning by specification in context.
}

\section{AG : ah oui ils y ont des rideaux IRF hein}

Ah yes they have curtains havn't they

Let us assume, that there are shutters (p), curtains (q), or nothing at all (r) at the windows, i.e. the implicit question that $\mathrm{YM}$ answers with his assertion is QUD $=\{\mathrm{p}, \mathrm{q}, \mathrm{r}\}$. Then his utterance only partially resolves this issue, YM only excludes possibility $\mathrm{p}$ and leaves the remaining options for further discussion.

\begin{tabular}{|l|l|l|}
\hline utterance & presupposition & QUD \\
\hline & & $\{p, q, r\}$ \\
\hline$\neg p \quad(=$ YM) & & \\
\hline & & $\{q, r\}$ \\
\hline$q \quad(=A G)$ & $\{q\} \cup C$ & \\
\hline & $C=\{r\}$ & $\{q\}$ \\
\hline
\end{tabular}

AG accepts YM's proposal by his ah oui. Nevertheless he uses the "implication" contour for his utterance of ils ont des rideaux. But this time the presupposition of the contour can be resolved, because the original QUD is not restricted to a singleton, but to $\{\mathrm{q}, \mathrm{r}\}$. AG's assertion is not contradictory to YM's assertion. It tries to settle the original QUD raised but not completely resolved by YM. And this is why - to the extend of AG accepting YM as authority wrt. the original QUD - AG's assertion is understood as a confirmation request.

Our claim is that even cases of confirmation request, information retrieval, exclamation or politeness can be argued to be derived from the general unified meaning we proposed. The politeness effect in (4) is easy to explain on the basis of our contrast-based analysis.

(4) Context: the speaker, while opening a door, says to the hearer:

$$
\begin{aligned}
& \text { Après-vous IRF, cher Monsieur (deaccented) } \\
& \text { After you, Sir }
\end{aligned}
$$

The speaker asserts that he will go after the hearer (p) and, by means of the contour, contrasts his assertion with the proposition q to go first. Politeness follows as conventional implicature (suggesting that the speaker would never q, i.e. go first). But note, that q need not be uttered (or even thought) by the hearer.

\section{A corpus based evaluation}

In order to evaluate our semantic proposal of the meaning of the "implication" contour on conversational data, we carried out an analysis of all the occurrences of the contour in a one hour dialogue extracted from the CID corpus [26]. In this corpus, two male speakers, AG and YM, well-knowing each other, were gathered in an anechoic room and fitted out with individual microphones in order to be recorded on separated tracks. They were requested to talk freely about unusual events that have happened to them.

Thanks to the hearing and visual inspection of the sound tracks using Praat [27] carried out by the first author of the present paper, 167 occurrences of the "implication" contour were found. 62 were produced by speaker AG and 105 by speaker YM. 
We classified the occurrences into 12 different types of situations depending on different uses of the contour. Table 1 below shows the number of occurrences for each type of situation by speaker. The lines in italic correspond to uses for which the meaning is clearly defective (i.e. involves a contradiction or a contrast), what we have described as the crucial dimension of the contour's meaning.

\begin{tabular}{|l|c|c|}
\hline Type of situation & AG & YM \\
\hline Contradiction & 3 & 12 \\
\hline Correction & 7 & \\
\hline Auto-correction & 5 & 6 \\
\hline Disagreement, protest & 2 & 9 \\
\hline Contrast & 16 & 33 \\
\hline Paradox & 2 & 3 \\
\hline "Je sais pas" (I don't know) & 1 & 7 \\
\hline Adressee's incredulity & 10 & \\
\hline Confirmation request & 4 & 3 \\
\hline Information retrieval & 1 & 3 \\
\hline Exclamation (emphasis) & $3+1$ & $8+9$ \\
\hline Obviousness & 7 & 12 \\
\hline TOTAL & $\mathbf{6 2}$ & $\mathbf{1 0 5}$ \\
\hline
\end{tabular}

Table 1. Number of occurrences of the "implication" rise-fall for each type of situation by speaker.

These contradictory/contrastive items can be said to confirm the meaning proposed in section 2 above, especially by involving a contradiction between a proposition $\mathrm{p}$ and its negation $\neg p$, even if it is sometimes indirectly, i.e. $p$ is not the actual content of the utterance, or by involving a contrast between two incompatible referents or situations. Table 2 gives the proportions of the contradictory/contrastive occurrences versus the other occurrences by speaker. It shows that for both speakers, $70 \%$ of the occurrences of the "implication" contour are used in situations and with meanings that confirm our semantic proposal.

\begin{tabular}{|l|c|c|}
\hline Type of situation & AG & YM \\
\hline defective & $74 \%$ & $67 \%$ \\
\hline others & $26 \%$ & $33 \%$ \\
\hline
\end{tabular}

Table 2. Proportions of the defective occurrences of the "implication" rise-fall versus the other occurrences by speaker.

Here are some examples extracted from the dialogue under study that will make the claim more explicit.

(5) AG : non IRF ça se voyait peut-être je me rappelle plus trop mais je crois pas que ça se voyait IRF

No perhaps it was visible I don't remember well but I don't think it was visible

Example (5) illustrates a direct contradiction where the speaker AG explicitly negates his addressee's proposition.

(6) AG: c'est des châtaignes IRF ben bien sûr IRF ouais il y a que ça IRF qui est comestible

That's chestnut of course yeah only this is good to eat

In (6), the first contour contrasts with anybody's (except the speaker's) potential assumption that it's not des chataîgnes, but des marrons, the second expresses obviousness (as shown by the words), and the third reinforces the contrast already expressed by the first. Here, the disagreement is not with the addressee, but with a general opinion. The contour on bien sûr (of course), shows that even the obviousness use indeed refers to a potential or actual disagreement.

The case of the expression Je sais pas (I don't know) is more difficult to explain but also very regular in the corpus. It is used idiomatically with the "implication" contour, once by AG but 7 times by $\mathrm{YM}$, in order to refute in advance the implicit request by the addressee of certified information due to Grice's cooperation principle [28]. Hence, these systematically implicate "I should know" (i.e. $\neg$ p). Example (7) illustrates this case.

(7) YM: et c'était des glaces y avait je sais pas IRF quinze litres de glace

And that was ice cream there were I don't' know fifteen liters of ice cream

Even cases of confirmation request, information retrieval and exclamation can be argued to be derived from the general unified meaning we proposed. Confirmation requests involve an issue $\{p, \neg p\}$ and a commitment of the speaker towards $p$. Information retrieval examples refer to the presence versus absence of the relevant information. Finally, exclamative or emphatic items rhetorically refer to the incredibility of the information. In all three cases, a potential alternative $\neg p$ is implicated.

\section{Conclusion}

In this paper, a unified and detailed meaning is proposed for French "implication" contour. This meaning centrally relies on an underspecified presupposition of contrast. The interpretative task of justifying this presupposition in context explains why the contour appears disguised in different kinds of meaning, labeled by other authors as obviousness, exasperation, politeness, emphasis, confirmation request, information retrieval, etc. This unified meaning reliably explains most of the uses of the contour in a spontaneous dialogue extracted from the CID corpus. These results give important support to two important theoretical issues: i) meaning (and especially intonational meaning) presuppose "inquisitive" components ([8], [10]), and ii) Gussenhoven's "linguistic normalcy" view, that intonational contours have meaning on their own [29].

\section{Acknowledgements}

This research is funded by a grant from the French National Research Agency (ANR-12-BSH2-0001-01; "PhonIACog: The role of the Initial Accent in prosodic structuring in French - From phonology to speech processing. 


\section{References}

[1] Delattre, P., "Les dix intonations de base du français", The French Review : 40, 1966.

[2] Rossi, M., "Vers une théorie de l'intonation", in Rossi et al. [Eds] L'intonation : de l'acoustique à la sémantique, Paris : Klincksieck, 1981.

[3] Rossi, M., "L'intonation, le système du français : description et modélisation", Paris : Ophrys, 1999.

[4] Di Cristo, A.and Hirst, D., "Vers une typologie des unites intonatives du français", 16émes Journées d'Etude sur la parole, Société française d'acoustique (ed.), Avignon, 219-222, 1996.

[5] Mertens, P., "Syntaxe, prosodie et structure informationnelle : une approche prédictive pour l'analyse de l'intonation dans le discours". Travaux de Linguistique 56(1), Duculot, 87-124, 2008.

[6] Ladd, R. D., "Intonational Phonology". Second edition: Cambridge University Press, 2008.

[7] Ginzburg, J., "The Interactive Stance: Meaning for Conversation", Oxford, 2012.

[8] Beyssade, C. and Marandin, J.-M., "French intonation and attitude attribution", In P. Denis, E. McCready, A. Palmer, and B. Reese (Eds) Proceedings of the 2004 Texas Linguistics Society Conference: Issues at the Semantics-Pragmatics Interface, 2007.

[9] Gunlogson, C." A question of commitment". In De Brabanter, P. and Dendale, P. (Eds) Commitment, 101136, 2008.

[10] Groenendijk, J. and Roelofsen, F., "Inquisitive semantics and pragmatics". Presented at the Workshop on Language, Communication, and Rational Agency at Stanford, May 2009.

[11] Westera, M., “' 'Attention, I'm violating a maxim!' A unifying account of the final rise", in Fernández, R. and Izard, A. (Eds) Proceedings of the 17thWorkshop on the Semantics and Pragmatics of Dialogue, Amsterdam, decembre 2013.

[12] Portes, C. and Reyle, U., "Intonational meaning triggers expectations", poster at Discourse Expectations: Theoretical, Experimental and Computational Perspectives, Tübingen,

[13] Krifka, M., "Negated polarity questions as denegations of assertions", in F. Kiefer and C. Lee (Eds) Contrastiveness and scalar implications. Springer. 2013.

[14] Post, B., "Solving a controversy in the analysis of French rising pitch movements", Proceedings of ICPhS1999. San Francisco, 965-968, 1999.

[15] Post, B., "Tonal and phrasal structures in French intonation", published $\mathrm{PhD}$ dissertation, The Hague: Holland Academic Graphics, 2000.

[16] Portes, C., "Prosodie et économie du discours : Spécificité phonétique, écologie discursive et portée pragmatique de l'intonation d'implication". $\mathrm{PhD}$ thesis, Aix-Marseille Université, 2004.

[17] Jun, S.-A. and Fougeron, C., "A phonological model of French intonation", in A. Botinis (Ed.), Intonation: Analysis, modelling and technology. Kluwer, Boston, 2000.

[18] Bigi, B., Portes, C.; Steuckardt, A. and Tellier, M., "Multimodal Annotations and Categorization for Political
Debates", Proceedings of ICMI Workshop on Multimodal Corpora for Machine learning, Alicante, Spain, 2011.

[19] Stalnaker, R., "Assertion", Pragmatics, Syntax and Semantics, 9, 1978.

[20] Portes, C. and Beyssade, C., "Is intonational meaning compositional", Verbum, forthcoming.

[21] Lascarides, A. and Asher, N., "Agreement and disputes in dialogue", Proceedings of the 9th SIGdial Workshop on Discourse and Dialogue, Stroudsburg, PA, USA, 29-36, 2008.

[22] Roberts, C., "Information structure in discourse: Towards an integrated formal theory of pragmatics". Ohio State University Working Papers in Linguistics, 49, 1996.

[23] Büring, D., "On d-trees, beans, and b-accents", Linguistics \& Philosophy, 26:5:511-545, 2003.

[24] Rooth, M., "A theory of focus interpretation", Natural Language Semantics 1,75-116, 1992.

[25] Reyle, U., Portes, C., "The meaning of French H*L\%contour". In Proceedings of the 17th Workshop on the Semantics and Pragmatics of Dialogue (DialDam), Amsterdam: December 2013.

[26] Bertrand, R., Blache, P., Espesser, R, Ferré, G., Meunier, C., Priego- Valverde, B., Rauzy, S. "Le CID - corpus of interactional data - annotation et exploitation multimodale de parole conversationnelle », Traitement automatique des langues (TAL), 105-134, 2008

[27] Boersma, P. and Weenink, D. "Praat: doing phonetics by computer [Computer program]". Version 5.3.60, retrieved 8 December 2013 from http://www.praat.org/

[28] Grice, H. P., "Logic and conversation", in Cole P. and Morgan, J., L. (Eds) Syntax and Semantics III: Speech Acts. Academic Press, New York, NY, 41-58, 1975.

[29] Gussenhoven, C. "A semantic analysis of the nuclear tones in English", in C. Gussenhoven, On the Grammar and Semantics of Sentence Accents, 193-267. Foris, Dordrecht, The Netherlands, 1983. 